\title{
Oral health and dental care in Hong Kong \\ Short title: Dental Care in Hong Kong
}

\section{C.H. Chu, S.S.S. Wong, E.C.M. Lo}

Faculty of Dentistry, The University of Hong Kong, Hong Kong SAR, China

Key words: Oral health, dental care, Hong Kong, Caries, Periodontal disease, ancillary staff

\author{
Correspondence to : $\quad$ Dr C.H. Chu, FDSRCSEd \\ 1B30 Prince Philip Dental Hospital \\ 34 Hospital Road \\ Hong Kong SAR, China \\ Tel: +852 2859 0287; \\ Fax: +852 2559 9013; \\ Email: chchu@.hku.hk
}




\title{
Oral health and dental care in Hong Kong
}

\begin{abstract}
Hong Kong, a Special Administrative Region of People's Republic of China, is a metropolitan city in Asia with a population of over 7 million people. This paper reflects the current oral health and dental care situations in Hong Kong. Water fluoridation was commenced in 1961, with a current level at $0.5 \mathrm{ppm}$. And there has continuously been lower caries prevalence thereafter. Dental care is mainly provided by private practitioners. The School Dental Care Service, run by the Department of Health, provides dental care to enrolled primary school children through treatments by dental therapists. An Oral Health Education Unit is set up to promote dental health among the public, particularly preschool children. Government dentists serve mainly civil servants and their dependents. Limited emergency dental care is available to the public at designated government clinics for pain relief, most commonly in the form of extractions. There are about 2,200 registered dentists and the dentist to population ratio is about 1:3,200. Amongst the dental team, dental hygienists are trained in limited numbers. There are only less than 320 dental hygienists registered, working under the supervision of dentists. The Faculty of Dentistry of the University of Hong Kong has been providing 5-year undergraduate training in dentistry since 1981, and this is lengthened to 6 years from 2012 onwards. Specialty training requires at least a further 6 years. There are 8 specialties, which are Community Dentistry, Endodontics, Family Dentistry, Oral \& Maxillofacial Surgery, Oral Rehabilitation, Orthodontics, Pediatric Dentistry, and Periodontics.
\end{abstract}




\section{Oral health and dental care in Hong Kong}

\section{Introduction}

Hong Kong is located on the southeast coast of the People's Republic of China (Figure 1), next to the Guangdong Province. Facing the South China Sea, it has a total area of 1,054 square kilometers and consists of 262 islands. It became a colony of the United Kingdom in 1842. And in 1997, the sovereignty of Hong Kong was returned to the People's Republic of China and it becomes a Special Administrative Region (SAR). Under the principle of "one country, two systems", Hong Kong has a political system different from that of mainland China and enjoys a "high degree of autonomy". Over the years, the population of Hong Kong has grown from less than one million people in 1945 to over seven million at mid-2010 (Information Services Department 2012). In addition to population growth, Hong Kong has also been going through other forms of modernization, for instance, in infrastructure and education. And there have been obvious changes in numerous socioeconomic indicators, such as increased proportion of the population engaged in trade, service, and finance. Hong Kong has high international rankings in various aspects such as quality of life, Human Development Index, corruption perception, economic freedom and financial and economic competitiveness. Since 1983, Hong Kong Dollar has been pegged to the US Dollar, currently at US\$ $1=\mathrm{HK} \$ 7.8$. The per capita of Gross Domestic Product (GDP) in 2011 is about US\$ 34,100 (Hong Kong Special Administrative Region Government, 2012).

The majority (93\%) of the population is Chinese (Census and Statistics Department, 2011). Indonesians and Filipinos respectively make up $2 \%$ of the population, while British make up $0.5 \%$. Similar to other developed regions, one of the demographic characteristics is the aging of the population. With the median age of the population at 42 , about $12 \%$ of the population is below fifteen year-old (Figure 2), and around 31\% are aged 45 to 64 and around 13\% are elderly of 65 year-old or older (Census and Statistics Department, 2011). The total expenditure on health is approximately 5\% of GDP in 2011. (Centre for Health Protection, 2012).

Hong Kong enjoys one of the lowest mortality rates in the world, which is comparable to countries such as Japan, Switzerland, and Sweden. In 2010, the death rate was 6.0 per 1,000 people 
within the population. And the male and female average life expectancy is 80.5 and 86.7 years, respectively. Similar to that of other developed countries, there have been decline in incidences of infectious diseases, and infant (1.3 per 1,000 live births in 2011) and maternal mortality rates (1.0 per 100,000 live births in 2011). There are about 13,000 medical doctors and the doctor to population ratio is about 1:550. (Centre for Health Protection, 2012)

\section{Dental Public Health Measures - Water fluoridation}

The most significant oral health initiative in Hong Kong was the introduction of water fluoridation in 1961. Domestic water supply in Hong Kong could reach nearly the entire population, including those living in rural areas and major outlying islands. It was introduced initially at 0.8 parts per million (ppm). Water fluoridation has been beneficial to the local population's dental health ever since it has been implemented. In 1960, caries experience in mean DMFT was 4.4 (Evans and Stamm, 1991). After water fluoridation was introduced, the mean DMFT was lowered to 1.5 in 1968 , which was further decreased to 0.8 in 2001 . The initial fluoride concentration of $0.8 \mathrm{ppm}$ was subsequently increased to $1.0 \mathrm{ppm}$ in 1976 . This concentration was considered excessive as a survey found that dental fluorosis prevalence among children aged 7 to 12 was $64 \%$. In response, the fluoride concentration was adjusted to $0.7 \mathrm{ppm}$ in 1986 and further reduced to $0.5 \mathrm{ppm}$ in 1988 (Evans and Stamm, 1991). In 2001 Oral Health Survey, the prevalence of fluorosis in Hong Kong declined to 9\%.

\section{Dental Public Health Measures - Oral health promotion}

The Dental Association of Hong Kong and the Oral Health Education Unit of the Department of Health have been organizing various campaigns to promote oral health. Dental health messages are disseminated through advertisements in local television, radio and newspaper, supplemented by posters displayed in public venues. The first "Love Teeth Day" began on September 20, 2003 with the aim to raise public awareness on oral health. The Love Teeth Day in 2010 and 2011 was held on December 9th.

\section{Oral health conditions}

Despite the benefits offered by water fluoridation, survey reported that about $51 \%$ of the preschoolers were still suffering from dental caries, which most of them were left untreated (Chu 
et al., 1999). The caries experience in mean dmft of the 5-year old children was 2.3. For the 12year old children, the caries experience in mean DMFT was 0.8, and 62\% of them had caries experience (Department of Health, 2001). Overall, the adult population in Hong Kong is still characterized by high caries prevalence of around 80 to 90\% (Department of Health 2001). However, many caries were left untreated. Middle aged people (35 to 44 year-olds) had a mean DMFT of 7.4, and $4 \%$ had root caries. The elderly people (65 to 74 year-olds) had a mean DMFT of 17.6 and $23 \%$ of them were found with root caries.

The periodontal condition of the adults in Hong Kong was found to deteriorate as the population gets older (Department of Health, 2001). It was found that most children had gingivitis, with only $6 \%$ of the 12 years olds had healthy gums (Department of Health, 2001). Calculus was found in many (60\%) of them. Moving on the adults, only 1\% of 35-44 years had healthy gums, and almost all (96\%) had calculus and nearly half (46\%) had deep pockets. In elderly population over 65 year-old, it was found that all of them suffered from bleeding gums; most (98\%) had calculus and more than half (55\%) had deep pockets (Department of Health, 2001). This is indicative of the essential needs of regular professional care like scaling and polishing of teeth.

The incidence rate of oral cancer in Hong Kong is 0.8 per 100,000 among the females and 1.0 per 100,000 among the males, and the mortality rate is 0.1 per 100,000 and 0.3 per 100,000 respectively (Census and Statistics Department, 2011). The majority (90\%) of oral cancer is found to be squamous cell carcinoma (SCC). One of the most common forms of SCC in Hong Kong is nasopharyngeal carcinoma (NPC). The incidence is approximately 30 times higher than that in the United States and Europe. However, significant improvement in prevention and control has been shown (McMillan, 2003).

\section{Oral health practices}

The oral health condition of the population is largely influenced by the daily oral health practices of the individual. Daily tooth brushing is practiced by over $90 \%$ of the population (Department of Health, 2001). The use dental floss for interdental cleaning, however, is found to be uncommon. Instead, it is found that the majority of the population uses toothpicks. In Hong Kong, oral health care products are widely available and can be accessed conveniently. In addition, 
more than $95 \%$ of the toothpaste in the market is fluoridated. Unfortunately, studies reported that the awareness of the public on oral health remained low although there were numerous advertisements on oral health care products. In fact, the majority of the population placed oral health matters relatively low in priority (Schwarz and Lo, 1994). The knowledge of the general public on oral diseases varied (Schwarz and Lo, 1994): people generally have fairly good understanding of dental caries and the ways to prevent them; however, there seem to have a lack of knowledge on periodontal diseases and its prevention.

\section{Oral health care systems}

The majority of dental service in Hong Kong is provided by private sector. It is a competitive market where there is no regulation on fees, and as a result there are huge variations in treatment fees and services provided. However, there are strict ethical guidelines with respect to advertising (Dental Council of Hong Kong, 2011). Most dental practices are either solo or small group practices of general practitioners.

In addition, around 40 non-governmental organizations (NGOs) provide dental services. Such organizations are usually social service agency, welfare organization, religious group, and labor union. The daily operation of these dental services is similar to that of a private practice. Many of these dental services provide basic dental care to the public and target people in lower socioeconomic or disadvantaged groups. These dental services receive virtually no subsidy from the government and the NGOs are responsible for recovering their own running cost.

The Department of Health has about 230 dentists working in Government Dental Clinics to provide comprehensive care to approximately 300,000 civil servants and their dependents and

civil servant pensioners. In addition, they also provide emergency dental services, limited to pain relief and extraction, to the public at designated clinics. Also under the Department of Health, Oral Maxillofacial Surgery and Dental Units provide specialist and emergency dental services to public hospitals' in-patients and referred patients, including patient groups with special oral health care needs. 
Despite the limited dental care provided to the public, the Government has set up School Dental Care Service offering services to all primary school children, usually aged six to twelve (Department of Health, 2001). This School Dental Care Service was started in 1980 and has been running through nine centralized clinics. Enrolment into the program has been voluntary, and can be done through the school the child is enrolled in. Around $90 \%$ of the primary school children in Hong Kong are eligible for the service. Furthermore, since there is only a nominal annual enrolment fee of about 2.5 USD (20 HKD), it provides a cheap and convenient mode for children to receive dental care from dental therapists under the direct supervision of government dental officers. Treatments provided include general preventive and restorative care, while orthodontics and advanced care are excluded. Currently, approximately 450,000 children are enrolled in the program currently.

The Oral Health Education Unit of the Department of Health aims to promote oral health to the general public, in particular to preschool children, in Hong Kong (Oral Health Education Unit, 2011). A dedicated website "Tooth Club" is developed to disseminate oral health messages to the public through the Internet. The Oral Health Education Unit also produces various oral health information materials including leaflets, brochures and VCDs for free distribution to local schools and organizations. In addition, a range of education materials such as games, exhibits and models are available for free loan service to local organizations. Kindergartens and nurseries also organize trips to its "Brighter Smiles Playland". There, through interactive activities, children absorb and obtain oral health knowledge. Overall, the proper uses of oral health care services are facilitated through the help of the government.

Last but not least, the government has implemented a Healthcare Voucher Scheme in 2008 (Cheung et al., 2008). This scheme is being offered to people aged 65 to 69 years who are entitled to apply for Normal Old Age Allowance. This scheme entitles these elderly people five annual vouchers of about US\$ 6 (HK\$ 50) each, which are to be utilized on medical and dental expenses. In general, it has been found that the majority of the elderly appreciates the proposed scheme. The number of the vouchers was subsequently increased to ten per year from 1st Jan 2012. However, many of the elderly still find a total amount of about US\$ 60 (HK\$ 500) per year to be too little to subsidize their health care expenditures. 


\section{Dentist Profile}

Before the 1980s, dentists working in Hong Kong were trained abroad in countries such as the Philippines, the United Kingdom (UK) and Australia. In 1980, a dental school was established to train dentist meeting the requirements set by the General Dental Council of the UK. Graduates are granted a degree in Bachelor of Dental Surgery. The first batch of 70 dental graduates started practicing dentistry in 1985. The dental school became the Faculty of Dentistry of the University of Hong Kong and is based at the Prince Philip Dental Hospital. It is at present the only institution providing dental education in Hong Kong. Currently, it recruits around 53 students per year. The training is five years in duration, which will be lengthened to six years from 2012 on. By 2011, more than 1,300 dentists have been trained by the Faculty of Dentistry, and they are not required to take licensing examination prior to practicing dentistry after graduation. However, dental graduates trained aboard have to pass the licensing examination prescribed by the Dental Council of Hong Kong before they can practice dentistry in Hong Kong. There are about 1,900 registered dentists and the dentist to patient ratio is about 1:3,800. The majority of them (73\%) work in private practice. About $18 \%$ moves onto the public sector such as the government, $3 \%$ practice in nongovernmental organizations and the rest pursue further postgraduate training or work under academic institutions.

The Faculty of Dentistry offers degrees in Master of Dental Surgery to provide advanced training in various disciplines such as orthodontics, periodontology and prosthodontics (Faculty of Dentistry, 2010). In 1993, the College of Dental Surgeons of Hong Kong was founded to manage and promote advanced dental training and research. There are 8 recognized specialties, which are community dentistry, endodontics, family dentistry, oral \& maxillofacial surgery, orthodontics, pediatric dentistry, periodontology, and prosthodontics (Ho et.al, 2008). Becoming a dental specialist in Hong Kong requires a minimum of 6 years of postgraduate training. This generally includes a 3-year study for a Master Degree (basic training) and another 3 years of supervised clinical practice (higher training). In 2011, most dentists (86\%) are general practitioners. Approximately $11 \%$ are specialists, $2 \%$ are involved in teaching and research and $1 \%$ of the dentists are part of business management. 


\section{Para-dental staff}

Other than dentists, there are also other dental ancillaries, who work as part of the dental team. That includes operating dental ancillaries as dental therapists, dental hygienists, dental surgery assistants and dental technicians.

Dental therapists work under the supervision of dentists in Government clinics. As of 2005, 304 dental therapists were enumerated. They are trained and employed by the department of Health. They received 3 years of in-service training and passed the Dental Therapist Certificate Examination. They are the main service providers within the Government School Dental Care Service, providing services including oral health education, scaling and polishing, fluoride application, sealants application, radiograph taking, simple restorations and simple extractions. In general, the dental therapists provide dental treatments to children under the age of 18 years. However, they also participate in educating and promoting basic oral health knowledge to the general public. A number of them received advanced training in New Zealand and became senior dental therapists. In these cases, they may perform pulp therapy under dentist's supervision.

Dental hygienists are registered professionals and they may work in private, government, public organizations and academic institutions. In 2008, there are 252 registered dental hygienists, of which 130 of them are active. Most recent data has shown 50\% of them to be in the private sector (Luciak-Donsbergera and Chan, 2003). The first dental hygienists were trained overseas in the 1970s. In 1980, the Prince Philip Dental Hospital embarked on offering a one-year program in dental hygiene. In 2005, the curriculum was expanded to a 2-year Higher Diploma in Dental Hygiene jointly run by the PPDH and the Community College of the University of Hong Kong. Dental hygienists provide cleaning and polishing of teeth, scaling to remove tartar, application of topical fluorides and sealants, taking dental radiographs and oral health education. It is important to note that all dental treatments provided must be prescribed by a dentist, who must be available in the premises at all times while the dental hygienist performs the prescribed treatments.

Dental surgery assistants (DSAs) work with dentists to provide dental care to patients. They are not legally required to register. In 2005, a total of 2392 dental surgery assistants were enumerated. A little over $80 \%$ were employed by private dental practices. And around $10 \%$ of 
them were employed by the Department of Health, while 5\% were employed by various institutions. Some dental surgery assistants were trained in the 1980s at the Hong Kong Polytechnics and in the Department of Health through in-service training (Chung et al., 2007). Many others were trained at the Prince Philip Dental Hospital, which provides a 1-year full-time certificate program in dental surgery assisting. Responsibilities of DSAs include patient reception, appointment bookings, answering enquiries, receiving payments, stock keeping and ordering, chair-side assisting, sterilization and dental health education (Chung et al., 2007). They are very important members in the dental team and are essential participants in four-handed dentistry.

Dental technicians work mainly in dental laboratories. They do not need to be registered.. As of 2005, 398 dental technicians were enumerated, 310 (78\%) were employed by the private sector, followed by 48 (12\%) employed by the Government and 40 (10\%) by the academic institutions. Dental Technicians are responsible for the production of all removable and fixed appliances, such as complete and partial dentures, orthodontic appliances, crowns, bridges and maxillo-facial prostheses. The Prince Philip Dental Hospital offers a two-year full-time dental technician training course, leading to the award of a General Diploma in Dental Technology.

\section{Conclusion}

Hong Kong is a metropolitan city of China, with a population of over 7 million people. Caries experience of the people declined after water fluoridation in 1960s. Fluorosis was found to be prevalent but is low when the fluoride concentration reduced to $0.5 \mathrm{ppm}$. Dental caries is still a significant oral health problem and prevalence of periodontal diseases increases with age. Dental awareness of the public remains low and many consider oral health relatively low in priority. There are about 2,000 dentists serving the public, mainly as private practitioners. The dentist to population ratio is 1:3,800. The Department of Health established the School Dental Care Service to serve primary school children. It also set up the Oral Health Education Unit to promote dental health through oral health education. There is only one dental school in Hong Kong, which trains around 50 dentists annually. Dental specialty training requires at least six years, and there are about 200 dental specialists in various disciplines. Other than dentists, there are dental therapists, dental hygienists, dental surgery assistants and dental technicians, all working as part of the dental team. 


\section{References}

1. Information Services Department (2012). Hong Kong: The Facts. [Online]. January 2012. [cited 2012 Aug 24]; Available from: URL:

http://www.gov.hk/en/about/abouthk/factsheets/docs/population.pdf

2. Census and Statistics Department (2012). Other Demographic Characteristics. In 2011

Population Census - Summary Results, p 37. [Online]. February 2012. [cited 2012 Aug 28]; Available from: URL:

http://www.census2011.gov.hk/pdf/summary-results.pdf

3. Census and Statistics Department (2012). Population Size and Structure. In 2011 Population Census - Summary Results, p 26. [Online]. February 2012. [cited 2012 Aug 28]; Available from: URL:

http://www.census2011.gov.hk/pdf/summary-results.pdf

4. Hong Kong Special Administrative Region Government (2012). Hong Kong - the Fact [Online]. August 2012 [cited 2012 Aug 28]; Available from: URL:

http://www.gov.hk/en/about/abouthk/facts.htm

5. Centre for Health Protection (2012). Health facts of Hong Kong [Online]. August 2012 [cited 2012 Aug 28]; Available from: URL:

http://www.dh.gov.hk/english/statistics/statistics_hs/files/Health_Statistics_pamphlet_E.pdf

6. Census and Statistics Department (2011). Vital Events [Online]. 15 February 2011[cited 2011 Jun 10]; Available from: URL:

http://www.censtatd.gov.hk/hong_kong_statistics/statistical_tables/?charsetID=1\&tableID=0 04

7. Evans RW, Stamm JW. Dental fluorosis following downward adjustment of fluoride in drinking water. J Public Health Dent 1991;51:91-98.

8. Chu CH, Fung DS, Lo ECM. Dental caries status of preschool children in Hong Kong. Br Dent J 1999; 187:616-20.

9. Department of Health (2001). Oral Health Survey 2001 [Online]. 12 December 2002 [cited 2012 Jun 10]; Available from: URL:

http://www.dh.gov.hk/english/pub_rec/pub_rec_lpoi/files/ohsbk.pdf 
10. McMillan AS. Oral Health and Quality of Life Following Radiotherapy for Nasopharyngeal Carcinoma. J HK Coll Radiol 2003; 6:75-77

11. Schwarz E, Lo ECM. Dental Health Knowledge and Attitudes among the Middle-aged and the Elderly in Hong Kong. Community Dentistry and Oral epidemiology 1994; 22: 358-63

12. The Dental Council of Hong Kong (2011). Code of Professional Discipline for the Guidance of Dental Practitioners in Hong Kong [Online]. 15 July 2008 [cited 2011 Jun 10]; Available from: URL: http://www.dchk.org.hk/docs/code.pdf.

13. Cheung HHN, Fong STS, Lau DMC, Mak RLY, Man GWC, So KMK, Tai MTC, Yee SYY, Yuen CHC, Wong MCM. Health care voucher scheme and willingness to spend on dental care among Hong Kong elders. Hong Kong Dent J 2008; 5:84-92.

14. Department of Health (2011). Tooth Club. School Dental Care Service [Online]. 9 May 2011 [cited 2012 Aug 10]; Available from: URL: http://www.schooldental.gov.hk/wsmile/openning_e.htm.

15. Oral Health Education Unit (2011) Tooth Club [Online]. 29 October 2010 [cited 2012 Aug 10]; Available from: URL: http://www.toothclub.gov.hk/en/en_index.html.

16. Ho MCT, Chung AYK, Sit EKF. An update on postgraduate dental education in Hong Kong and a comparison of three countries. Hong Kong Dent J 2008; 5:60-6

17. Chung MY, Leung JLK, Hui KKKH. Dental surgery assistants in Hong Kong: history of training. Hong Kong Dent J 2007; 4:67-70

18. Faculty of Dentistry (2010). Taught Postgraduate Programmes. [Online]. 4 July 2010 [cited 2012 Aug 10] Available from: URL:

http://www.dental.hku.hk/learning/pg_tpg_prospectus.html\#menu

19. Luciak-Donsberger C, Chan CKP. Dental Hygiene in Hong Kong: a Global Perspective. Int J Dent Hyg 2003; 1: 84-8 
Figure 1 Map of China and location of Hong Kong

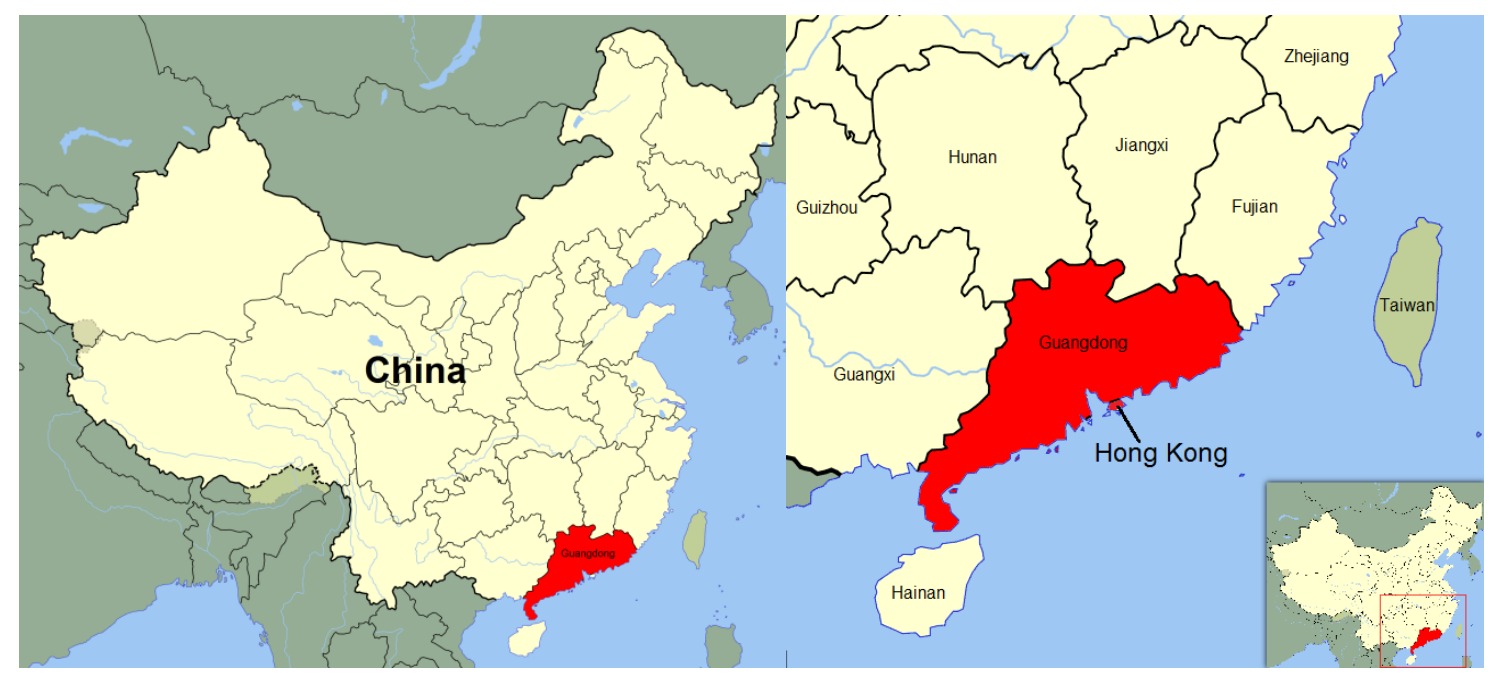

Figure 2 Distribution of the Age of the Hong Kong Population.

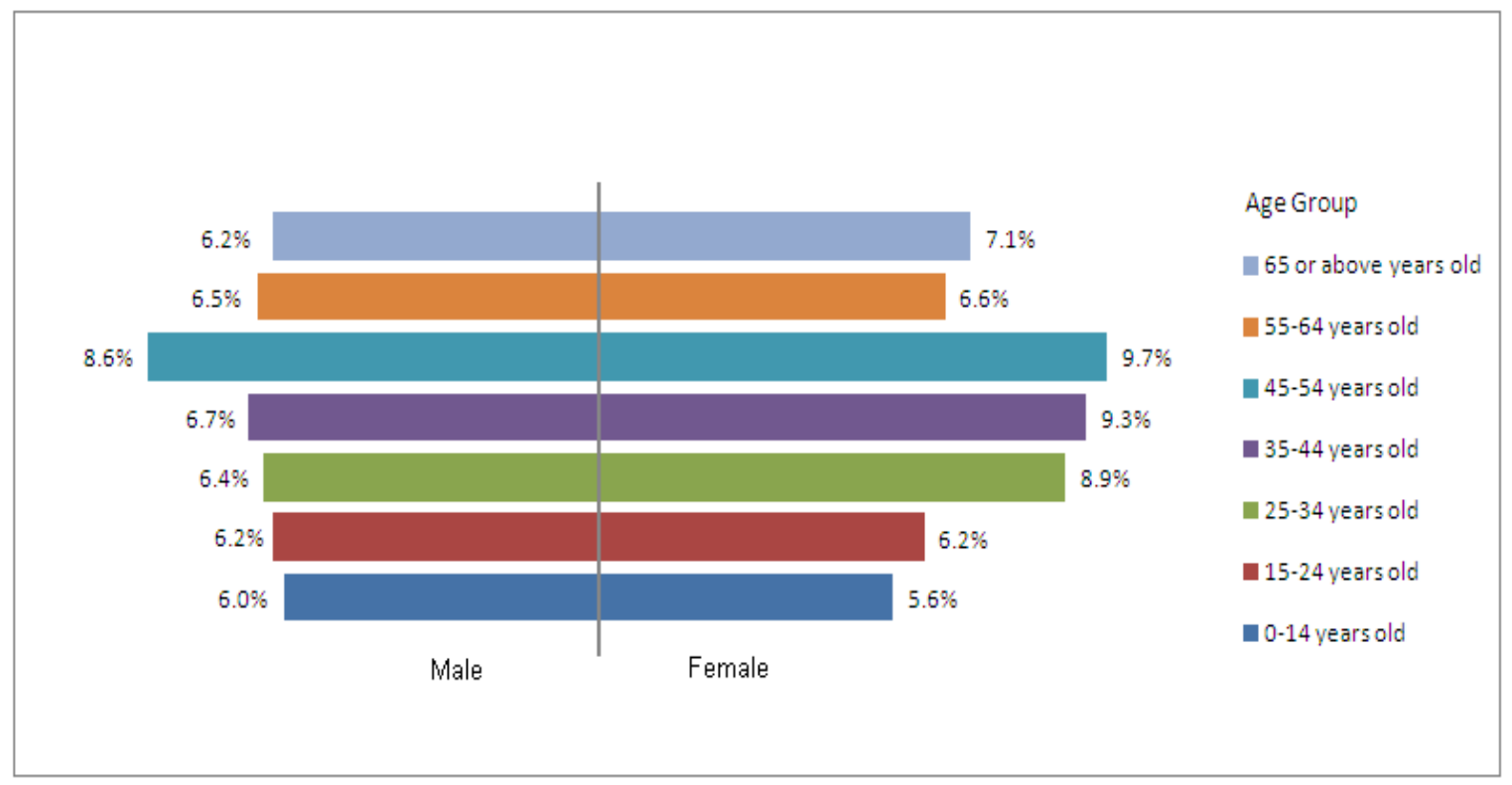

